\title{
Effect of Obesity and/or Ligature-induced Periodontitis on Aortic Wall Thickness in Wistar Rats
}

\author{
Andressa G. Moreira', Alessandra C. Nicolini' , \\ Eduardo J. Gaio', Fernanda Visioli2, \\ Cassiano K. Rösing' ', Juliano Cavagni' \\ 'Universidade Federal do Rio Grande do Sul, Faculdade de Odontologia, \\ Departmento de Periodontia, Rio Grande do Sul, Brasil. \\ 2 Universidade Federal do Rio Grande do Sul, Faculdade de Odontologia, \\ Departmento de Patologia Oral, Rio Grande do Sul, Brasil.
}

\begin{abstract}
The purpose of this study was to evaluate aortic wall thickness after periodontal disease and/or obesity induction in a Wistar rat model. Sixty male Wistar rats were randomly divided into four groups: control (CT), periodontal disease (PD), obesity $(O B)$, and obesity plus periodontal disease $(O B+P D)$. Groups $O B$ and $O B+P D$ received cafeteria diet for 17 weeks. After they had acquired obesity (week 12), periodontal disease was induced by placing a silk ligature on the maxillary right second molar of groups $P D$ and $O B+P D$. During the experimental period, body weight and Lee index were assessed. Mean alveolar bone loss $(A B L)$ was evaluated, and aortas were prepared for histometric analysis of the aortic wall by ImageJ software. Body weight and Lee index increased in rats exposed to cafeteria diet. Mean $A B L$
\end{abstract}

was higher in Groups $P D$ and $O B+P D$ than in control and $O B$ $(p<0.05)$. ABL was $18 \%$ higher in Group $O B+P D$ than in Group $P D$, with statistically significant difference $(p<0.001)$. Aortas were thicker in Groups $O B$ and $O B+P D$ than in control and $P D$ groups, respectively $(2.31 \mathrm{~mm} \pm 0.28$ and $2.33 \pm 0.29 \mathrm{vs} .2 .18 \pm$ 0.26 and $2.14 \pm 0.27)$. Group $O B$ differed significantly from the control group $(p=0.036)$, and $O B+P D$ and $O B$ differed significantly from $P D(p=0.004$ and $p=0.001$, respectively). Obesity alters aortic wall thickness in Wistar rats. However, the presence of periodontal disease did not affect the aortic wall thickness under the conditions of the present study.

Received: February 2020; Accepted: May 2020.

Keywords: obesity, alveolar bone loss, atherosclerosis, rats.

\section{Efeito da obesidade e/ou periodontite induzida por ligadura na espessura da parede da aorta em ratos wistar}

\section{RESUMO}

O objetivo deste estudo foi avaliar a espessura da parede da aorta após modelos de indução de doença periodontal elou obesidade em ratos Wistar. Sessenta ratos Wistar machos foram aleatoriamente divididos em quatro grupos: controle (CT), doença periodontal $(D P)$, obesidade $(O B)$, obesidade mais doença periodontal $(O B+D P)$. Os grupos $O B$ e $O B+D P$ receberam dieta de cafeteria por 17 semanas. Após de adquirirem obesidade, (semana 12), doença periodontal foi induzido pela colocação de ligaduras de seda no segundo molar superior direito dos grupos $D P$ e $O B+D P$. Durante o periodo experimental, o peso corporal e indice de Lee foram obtidos. Média de perda óssea alveolar (POA) foi avaliada e as aortas preparadas para análise histométrica da parede aórtica (em $\mathrm{mm}$ ) pelo software ImageJ. Ratos expostos a dieta de cafeteria demonstraram um aumento do peso corporal e do índice de Lee. Uma POA media maior foi

\section{INTRODUCTION}

Obesity is defined as a chronic multifactorial disease characterized by abnormal or excessive fat accumulation that represents a risk to health ${ }^{1,2}$. observada nos grupos DP e OB+DP comparado aos grupos controle e $O B(p<0.05)$. O grupo $O B+D P$, quando comparado ao grupo DP, apresentou POA 18\% maior e essa diferença foi estatisticamente significativa $(p<0.001)$. Os grupos $O B e$ $O B+D P$ exibiram uma espessura de aorta maior comparado aos grupos DP e controle, respectivamente $(2.31 \pm 0.28$ e $2.33 \pm$ 0.29 vs. $2.18 \pm 0.26$ e $2.14 \pm 0.27$ ). Diferenças significativas foram observadas nas comparações dos grupos $O B$ e controle $(p=0,036)$, e $O B+D P$ e $O B$ comparado ao grupo $D P(p=0.004$ e $p=0.001$, respectivamente). A obesidade parece afetar a espessura da parede da aorta em ratos Wistar. Entretanto, a presença de doença periodontal não afetou a espessura da parede da aorta sob as condições do presente estudo.

Palavras-chave: obesidade, perda óssea alveolar, aterosclerose, ratos.

Genetic and behavioral aspects are the main etiological factors.

Obesity is known to be a risk factor for cardiovascular diseases $(\mathrm{CVD})^{3,4}$, the main cause of death 
worldwide, caused mainly by atherosclerosis. Atherosclerosis involves the deposition of cholesterol and other lipids on arterial walls, followed by inflammation and fibrosis, which increase arterial wall thickness and protrude into the vessel lumen, thus affecting normal irrigation. Studies suggest that periodontitis may influence the development of atherosclerosis ${ }^{5,6}$. In addition, studies report that obese individuals with periodontal disease may have an increased risk of cardiovascular events ${ }^{7}$. The biological plausibility is that both conditions lead to prothrombotic and proinflammatory conditions ${ }^{8}$. Some animal studies have evaluated the correlation between periodontal disease and obesity regarding atherosclerotic events, reporting diverse results ${ }^{9,10}$ This study aims to evaluate aortic wall thickness, taken as an indicator of atherosclerosis, in rats exposed to induced periodontal disease (PD) and/or obesity (OB). We intend to contribute to assessing periodontal disease as an additional risk factor for the development of atherosclerosis.

\section{MATERIALS AND METHODS}

\section{Study design and ethical considerations}

This is a secondary analysis of a blinded, randomized, controlled animal model study ${ }^{11}$. The Animal Research Reporting In Vivo Experiments (ARRIVE) guidelines were followed ${ }^{12}$. The research protocol was approved by the Animal Research Ethics Committee of the Hospital de Clínicas de Porto Alegre, Brazil (protocol number 110051 at 26/04/2011). Fig. 1 shows the study flowchart.

\section{Animals}

We used sixty male 60-day-old Wistar rats, weighing approximately $350 \mathrm{~g}$ each. Animals were housed in groups of 4-5 under a 12-hour light/dark cycle at room temperature $\left(22^{\circ} \mathrm{C} \pm 2^{\circ} \mathrm{C}\right)$ with free access to water and the assigned diet. Two animals were lost during the experimental period, (one from Group $\mathrm{CT}$ and one from Group OB), for reasons unrelated to the protocol, as confirmed in the necropsies.

\section{Randomization and allocation to groups}

All animals were weighed and arranged in ascending order according to weight. Based on the distribution of this weight, rats were stratified into tertiles and randomized into 4 experimental groups, as follows:

Control (CT): received standardized rat chow diet and water.

Periodontal Disease (PD): exposed to ligatureinduced periodontal disease in the upper right $2^{\text {nd }}$ molar, with the same diet as CT.

Obesity (OB): obesity induction using a high-fat hypercaloric cafeteria diet (CAF).

Obesity and Periodontal Disease (OB+PD): exposed to obesity and periodontal disease induction, as described in Groups OB and PD.

\section{Cafeteria diet-induced obesity}

The CAF diet, used to induce obesity in rats, was composed of $55 \%$ carbohydrates, $20 \%$ lipids, $20 \%$ protein and $5 \%$ other constituents (sodium, calcium, vitamins, preservatives and minerals, among others). This high-calory diet included condensed milk, soda, sandwich cookies, wafer, sausage, cheese and ham snacks, provided at libitum following the criteria of Sampey et al. ${ }^{13}$ The control group animals were fed with standard chow. Water was available ad libitum for all groups. The CAF diet model is able to raise body weight and glucose levels, and to cause hyperlipidemia ${ }^{13}$. All foods were replaced daily to ensure freshness.

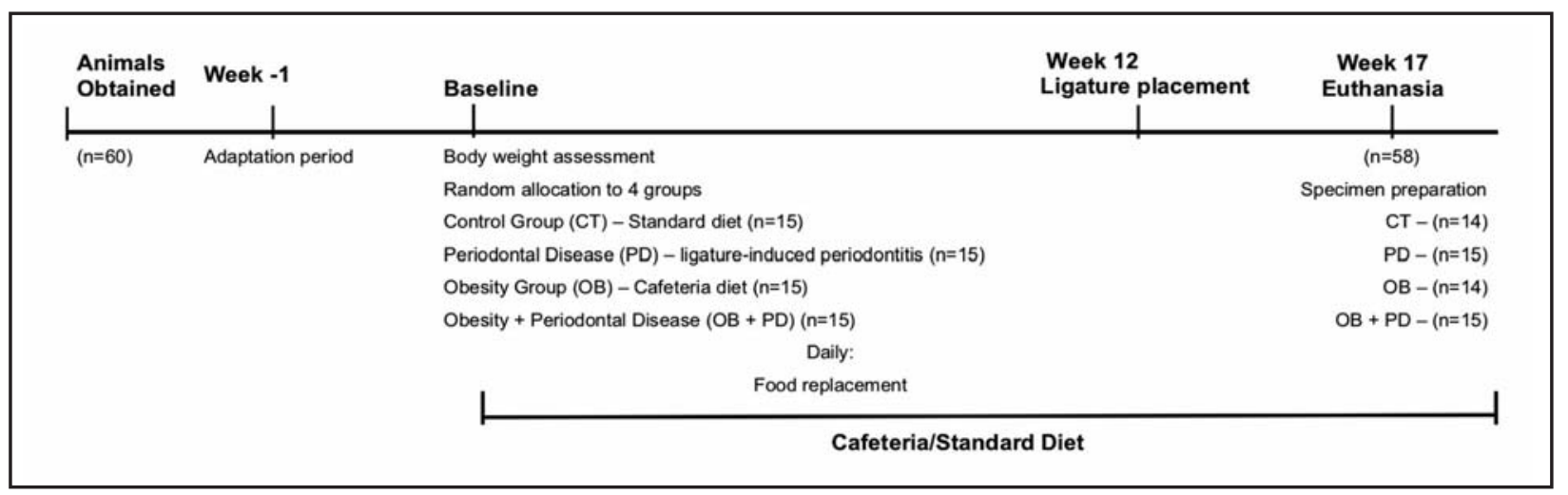

Fig. 1: Study Flowchart. 


\section{Body weight and Lee index assessments}

Animals were weighed on an electronic scale. The Lee index method ${ }^{14}$ was applied for rapid, accurate measurement of obesity in the groups fed on the cafeteria diet. The Lee index was calculated by dividing the cubic root of the body weight in grams by the naso-anal length in centimeters and multiplying by ten.

\section{Periodontal disease model}

At week 12, after groups under CAF diet had acquired obesity, periodontal disease was induced by placing a silk ligature on the maxillary right second molar, under general anesthesia with inhaled $5 \mathrm{~V} \%$ isoflurane (Isoforine ${ }^{\mathrm{TM}}$ Cristália, SP, Brazil) vaporized in $100 \%$ oxygen by facemask. All anesthetic procedures were performed by a veterinarian. The contralateral molar was used as intra-group control.

\section{Specimen preparation}

Animals were euthanized by decapitation 30 days after placing the ligature. Maxillaries were removed, sectioned, and de-fleshed in 9\% sodium hypochlorite for 2 hours. The aortic arteries were carefully removed, washed abundantly with saline solution and fixed with $10 \%$ buffered formalin for histological processing.

\section{Alveolar bone loss morphometric analysis}

Morphometric analysis was performed using standard digital photographs. Pictures were taken using a 6.1-megapixel digital camera (Nikon ${ }^{\mathrm{TM}}$ Coolpix, Ayutthaya, Thailand) attached to a tripod and equipped with $100 \mathrm{~mm}$ macro-lenses with minimal focal distance. Specimens were fixed to an endodontic ruler, parallel to the ground. Photographs were taken of the buccal and palatal aspects of right and left hemimaxillae.

Linear distances were measured from the cemento enamel junction to the bone crest, using Adobe Photoshop ${ }^{\mathrm{TM}} \mathrm{CS} 4$ software (Adobe Systems Inc., San Jose, CA, USA). An external researcher kept track of the groups to ensure that the examiner was blinded to them. Five measurements were taken on each surface of the second molar, both buccally and palatally (two on the distal root, two on the mesial root and one on the furcation). The measurements in pixels were converted into millimeters using the markings of the endodontic ruler to which the hemimaxillae were attached as reference.

\section{Histometric analysis of aortas}

The aortas were sectioned into four parts and embedded in paraffin, and $3 \mathrm{~mm}$ sections were cut for hematoxylin and eosin staining.

Microphotographs were taken at 100x magnification. The aortic wall (including intima and media) was measured $(\mathrm{mm})$ by means of ImageJ software. The thickest point of each section was selected for measurement. The examiner was blinded to group allocation during histometric analysis.

The examiner was calibrated before starting the histometric analysis. Twenty percent of the aorta slides were selected randomly and the examiner measured them twice, with a one-week interval between measurements. Their means were compared using Pearson's correlation coefficient. The absence of a statistically significant difference between means was considered an indication of reproducibility. The intra-class correlation coefficient was 0.61 .

\section{Statistical analysis}

For each evaluated parameter, normality was tested by Shapiro-Wilk test, and the appropriate statistical test was selected according to this assumption. Mean and standard deviation (SD) of body weight and Lee index were compared by Repeated Measurements one-way ANOVA followed by Bonferroni. Alveolar bone loss did not have symmetric distribution, therefore the data was evaluated by Kruskall Wallis followed by Dunn multiple comparison test and expressed in median and interquartile range. Aortic wall thickness was analyzed by one-way ANOVA, followed by Bonferroni's multiple comparison test. The level of significance was set at 0.05 .

\section{RESULTS}

\section{Obesity parameters}

Body weight increased in all experimental groups (Fig 2). As from week 10, body weight was significantly higher in Groups $\mathrm{OB}$ and $\mathrm{OB}+\mathrm{PD}$ than in Groups CT and PD.

Until week 12, the Lee index increased significantly in Groups $\mathrm{OB}$ and $\mathrm{OB}+\mathrm{PD}$ (Fig 3). In addition, a significant interaction among groups and between time and groups $(\mathrm{P} \leq 0.01)$ for this index was demonstrated by Repeated Measurements ANOVA. 


\section{Alveolar bone loss}

As expected, alveolar bone loss was significantly higher in groups with induction ligatures (PD and $\mathrm{OB}+\mathrm{PD}$ ) than in groups without induction (Fig.4). Interestingly, bone loss was $18 \%$ higher in Group OB+PD than in Group PD. $(\mathrm{p}<0.001)$.

\section{Aortic wall thickness}

Table 1 shows aortic wall thickness values. CAF diet induced significant increases, independently of the presence of periodontal disease. Statistically significant differences were found between $\mathrm{OB}$ and CT $(\mathrm{p}=0.036), \mathrm{OB}+\mathrm{PD}$ and PD $(\mathrm{p}=0.004)$, and OB and PD $(p=0.001)$. No statistically significant difference was observed between $\mathrm{CT}$ and $\mathrm{PD}$ or between $\mathrm{OB}$ and $\mathrm{OB}+\mathrm{PD}$.

\section{DISCUSSION}

The present study evaluated aorta wall thickness and its relation to obesity and/or periodontal disease in Wistar rats. The rationale for such a study is that the inflammatory response of periodontal disease

\begin{tabular}{|c|c|}
\hline Group & Thickness $(\mu \mathrm{m})$ \\
\hline CT & $2.18 \pm 0.26 \mathrm{~A}$ \\
\hline PD & $2.14 \pm 0.27 \mathrm{~A}$ \\
\hline OB & $2.33 \pm 0.29 B$ \\
\hline $\mathrm{OB}+\mathrm{PD}$ & $2.31 \pm 0.28 \mathrm{~B}$ \\
\hline
\end{tabular}

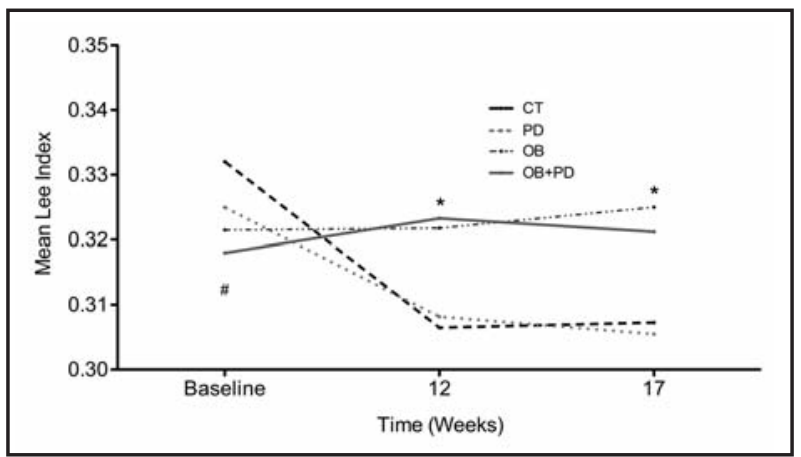

Fig. 3: Mean Lee Index according to experimental groups throughout the study. *Groups $O B$ and $O B+P D$ differed significantly from Groups CT and PD. \#After baseline, mean Lee Index increased in Groups $O B$ and $O B+P D$ and decreased in Groups $C T$ and $P D$ (Repeated Measurements ANOVA-Bonferroni). could be an additional factor in the pathogenesis of cardiovascular diseases, triggering atherosclerosis. The results demonstrated that obesity was able to increase aorta wall thickness; however, periodontal disease was not an additional modifier of wall thickness.

Cardiovascular diseases (CVD) have high morbidity and mortality rates worldwide ${ }^{1}$. It has been well established that atherosclerosis is the main factor in CVD etiopathogenesis. It is important to evaluate possible risk factors in addition to the established ones, and to ascertain whether they may worsen these health conditions. This would be helpful for establishing preventive and therapeutic strategies.

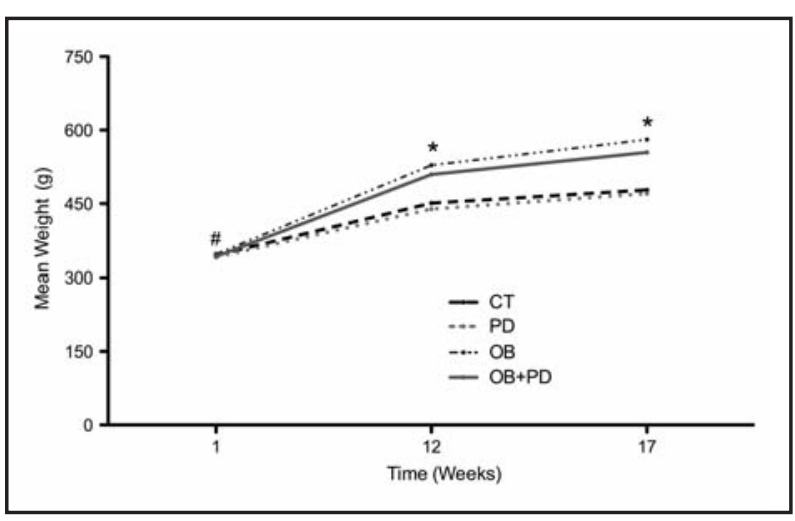

Fig. 2: Mean body weight (g) according to experimental groups throughout the study. *Groups $O B$ and $O B+P D$ differed significantly from Groups $C T$ and PD. \#After baseline, mean weight increased in all groups (Repeated Measurements ANOVA-Bonferroni).

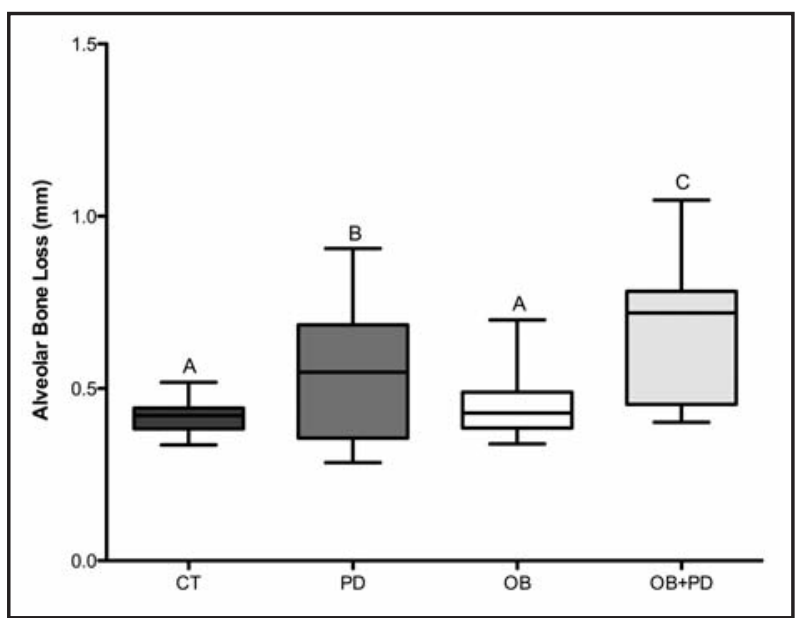

Fig. 4: Median and interquartile range (25th and 75 th percentile) of alveolar bone loss according to experimental groups. Different letters indicate statistically significant difference among groups (Kruskall Wallis - Dunn). 
Atherosclerosis involves inflammatory responses which have been related to other inflammatory conditions such as periodontal disease and cardiovascular risk factors, including obesity, smoking, sedentary lifestyle, dyslipidemia and diabetes ${ }^{15}$, all of which could increase the inflammatory burden and change the arterial endothelial function, which is the first stage of atherosclerosis. It has also been suggested that overweight and obesity may be associated with periodontal disease ${ }^{16}$. However, the exact biological process underlying this relationship has not yet been established.

Clinical studies using true outcomes such as myocardial infarction or even death are scarce and subject to ethical restraints. Animal studies are thus warranted. This study used Wistar rats, which are widely used in both periodontal and cardiovascular studies. The experiment induced obesity by feeding rats on cafeteria diet, which mimics the western diet, with high carbohydrate and fat intake. This diet has been used in a previous study. ${ }^{13}$ This kind of model has also been used in the study of pathogenesis of periodontitis and its association with metabolic abnormalities ${ }^{17,18}$.

In the first 12 weeks, before ligature placement, Groups $\mathrm{OB}$ and $\mathrm{OB}+\mathrm{PD}$ were fed cafeteria diet, which led to obesity ${ }^{13,17,18}$. Body weight and Lee index values were used as methods to infer obesity. At baseline, the rats weighed approximately $350 \mathrm{~g}$, with no statistically significant difference among groups. Body weight increased in all groups; however, as from week 10, the rats which received CAF diet had statistically significant higher body than Groups CT and PD. Additionally, the Lee index increased significantly in groups fed on cafeteria diet. Even though studies suggest that periodontitis may stimulate obesity by secretion of proinflammatory cytokines ${ }^{18}$, no significant differences were observed between $\mathrm{OB}$ and $\mathrm{OB}+$ PD with regard to body weight or Lee index in our study. Two parameters - body weight and Lee index - both showed that obesity occurred in the groups fed on CAF diet, thereby enabling the objectives of comparing how obesity and/or periodontal disease relates to potential negative cardiovascular outcomes.

Periodontal disease induction was effective, as shown by the mean values for alveolar bone loss which were considerably higher in the groups in which ligature was placed. Furthermore, alveolar bone loss was higher in Group OB+PD than in PD groups. These results corroborate previous findings reported by Verzeletti et al. ${ }^{18}$. These data suggested that in the presence of ligature, obesity acted as a synergistic factor in bone loss of inflammatory origin. A possible explanation for this synergism is that the continuous release of cytokines derived from the subclinical chronic inflammation which is characteristic of obesity may exacerbate other local inflammatory responses such as periodontal disease ${ }^{19}$.

Aortic walls were thicker in Groups $\mathrm{OB}$ and $\mathrm{OB}+\mathrm{PD}$ than in Groups CT and PD. This supports the concept that obesity increases aorta wall thickness, thereby increasing the chances of CVD. Induction of obesity by hypercaloric and hyperlipidic diet in Wistar rats produces major metabolic alterations, such as an increase in triglycerides. For this reason, the use of this model was suggested to investigate endothelial dysfunction ${ }^{20}$, which is one of the factors which impact the pathogenesis of atherosclerosis. Our measurement method proved to be effective to show an increase in aortic thickness of the rats which received the CAF diet. Similarly, other authors also observed increased aortic wall thickness in rats exposed to a high-fat content diet different from CAF. ${ }^{21}$.

In our model, periodontal disease did not modify the effect of obesity by either increasing or decreasing aortic wall thickness. There are several possible explanations for this, some of which would be worthwhile studying further. Firstly, the ligature was placed on only one tooth, which may produce a low inflammatory challenge compared to extensive periodontal disease. Secondly, aortic wall thickness is extremely variable but was only measured at one point. Nevertheless, the supporting literature is sufficient to warrant further studies of the relationship between periodontal diseases and CVD, in order to better guide preventive and therapeutic strategies. Furthermore, it should be highlighted that periodontal and cardiovascular diseases share risk factors, and should both be considered in the development of health policies.

In conclusion, obesity altered aortic wall thickness in Wistar rats. However, the presence of periodontal disease did not affect aortic wall thickness under the conditions of the present study. 


\section{FUNDING}

This work was supported by the Coordination for Enhancement of Higher Education Personnel, Brazil (CAPES - Grant PROCAD NF - 2008) and Incentive Fund for Research and Events of the Hospital de Clínicas de Porto Alegre, Brazil (FIPE Grant number 110051).

\section{REFERENCES}

1. World Health Organization. Obesity: preventing and managing the global epidemic. Report of a WHO consultation. World Health Organ Tech Rep Ser 2000; 894:1-253.

URL: https://www.who.int/nutrition/publications/obesity/ WHO TRS 894/en/

2. Smith KB, Smith MS. Obesity Statistics. Prim Care 2016; 43:121-135.

3. Kappus RM, Fahs CA, Smith D, Horn GP, Agiovlasitis S, Rossow L, et al. Obesity and overweight associated with increased carotid diameter and decreased arterial function in young otherwise healthy men. Am J Hypertens 2014; 27:628-634.

4. Yatsuya H, Li Y, Hilawe EH, Ota A, Wang C, Chiang C, et al. Global trend in overweight and obesity and its association with cardiovascular disease incidence. Circ J 2014;78:2807-2818.

5. Kinane DF, Lowe GD. How periodontal disease may contribute to cardiovascular disease. Periodontol 2000 2000; 23:121-126.

6. Teng YT, Taylor GW, Scannapieco F, Kinane DF, Curtis M, Beck JD, et al. Periodontal health and systemic disorders. J Can Dent Assoc 2002; 68:188-192.

7. Pires JR, Dos Santos IP, de Camargo LF, Zuza EP, de Toledo BE, Monteiro SC. Framingham cardiovascular risk in patients with obesity and periodontitis. J Indian Soc Periodontol 2014; 18:14-18.

8. Chistiakov DA, Orekhov AN, Bobryshev YV. Links between atherosclerotic and periodontal disease. Exp Mol Pathol 2016; 100:220-235.

9. Ekuni D, Tomofuji T, Irie K, Kasuyama K, Umakoshi M, Azuma T, et al. Effects of periodontitis on aortic insulin resistance in an obese rat model. Lab Invest 2010;90:348-359.

10. Jain A, Batista EL, Jr., Serhan C, Stahl GL, Van Dyke TE. Role for periodontitis in the progression of lipid deposition in an animal model. Infect Immun 2003; 71:6012-6018.

11. Cavagni J, de Macedo IC, Gaio EJ, Souza A, de Molon RS, Cirelli JA, et al. Obesity and Hyperlipidemia Modulate Alveolar Bone Loss in Wistar Rats. J Periodontol 2016; 87:e9-17.

\section{CORRESPONDENCE}

Dr. Cassiano Kuchenbecker Rösing

Rua Ramiro Barcelos, 2492

Bairro Santana, Porto Alegre - RS, Brazil

Zip Code: 90035-003

ckrosing@hotmail.com

12. Kilkenny C, Browne WJ, Cuthill IC, Emerson M, Altman DG. Improving bioscience research reporting: the ARRIVE guidelines for reporting animal research. Osteoarthritis Cartilage 2012; 20:256-260.

13. Sampey BP, Vanhoose AM, Winfield HM, Freemerman AJ, Muehlbauer MJ, Fueger PT, et al. Cafeteria diet is a robust model of human metabolic syndrome with liver and adipose inflammation: comparison to high-fat diet. Obesity (Silver Spring) 2011; 19:1109-1117.

14. Bernardis LL, Patterson BD. Correlation between 'Lee index' and carcass fat content in weanling and adult female rats with hypothalamic lesions. J Endocrinol 1968 Apr; 40: 527-528.

15. Orlandi M, Suvan J, Petrie A, Donos N, Masi S, Hingorani A, et al. Association between periodontal disease and its treatment, flow-mediated dilatation and carotid intimamedia thickness: a systematic review and meta-analysis. Atherosclerosis 2014; 236:39-46.

16. Keller A, Rohde JF, Raymond K, Heitmann BL. Association between periodontal disease and overweight and obesity: a systematic review. J Periodontol 2015; 86:766-776.

17. Cavagni J, Wagner TP, Gaio EJ, Rego RO, Torres IL, Rosing CK. Obesity may increase the occurrence of spontaneous periodontal disease in Wistar rats. Arch Oral Biol 2013; 58:1034-1039.

18. Verzeletti GN, Gaio EJ, Linhares DS, Rosing CK. Effect of obesity on alveolar bone loss in experimental periodontitis in Wistar rats. J Appl Oral Sci 2012; 20:218-221.

19. Pischon N, Heng N, Bernimoulin JP, Kleber BM, Willich SN, Pischon T. Obesity, inflammation, and periodontal disease. J Dent Res 2007; 86:400-409.

20. Rosini TC, Silva AS, Moraes C. Diet-induced obesity: rodent model for the study of obesity-related disorders. Rev Assoc Med Bras (1992) 2012; 58:383-387.

21. Turkay C, Saba R, Sahin N, Altunbas H, Ozbudak O, Akkaya B, Ozbilim G, Cölbasi I, et al. Effect of chronic Pseudomonas aeruginosa infection on the development of atherosclerosis in a rat model. Clin Microbiol Infect 2004; 10:705-708. 